\title{
The Travel Cost Method: An Empirical Investigation of Randall's
}

\section{Difficulty}

M. Common, T. Bull and N. Stoeckl ${ }^{*}$

\begin{abstract}
Randall (1994) argued that the Travel Cost Method, TCM, cannot do what it is supposed to do - generate monetary measures of recreation site benefits for use in Cost Benefit Analysis. Randall argues that what is relevant to recreational decision making is the subjective, and unobservable, price of travel, whereas TCM uses the observer-assessed cost of travel. Hence, TCM can at best give ordinally measurable welfare estimates. In this paper, 'Randall's Difficulty' is formulated as an estimation problem and results are derived for that problem. A survey data set and Monte Carlo simulations are used to illustrate and quantify Randall's Difficulty. The meaning of, prospects for, and usefulness of ordinal measurement are explored, and the existence of a solution to Randall's Difficulty is considered.
\end{abstract}

Key words: travel cost method, welfare estimates, cost measurement, ordinality.

\footnotetext{
"Mick Common, Graduate School of Environmental Studies, University of Strathclyde, Glasgow. Tim Bull, Australian Bureau of Agricultural and Resource Economics, Canberra. Natalie Stoeckl, Division of Management and Technology, University of Canberra, Canberra.
} 


\section{Introduction}

It is sometimes argued that the travel cost method (TCM) produces more reliable estimates than other valuation techniques such as, for example, the contingent valuation methodology (CVM). The reason offered is that TCM uses observed rather than hypothetical — data to generate results ${ }^{1}$. However, as usually implemented, the TCM does not use only observed data. Most travel cost studies use observed quantity data (visits), but the price, or travel cost, data are constructed by the researcher using observed data on distance, and conventions which convert distance to cost. A large subset of the travel cost literature focuses on problems arising in such conversion - for example, on how to allow for the opportunity cost of time and how to allocate joint costs for multiple-site visitors.

Randall (1994) argues that it is subjective costs that determine recreation decisions and that these costs are unobservable, forcing researchers to substitute their own cost estimates which are, inherently, poor approximations to true subjective costs. The conclusion he draws from this is that "welfare estimates remain artefacts of the travel cost accounting and specification conventions selected for imposition" (p. 93) so that "the best we can expect (from the TCM) is ordinally measurable welfare estimates" (p. 95).

Importantly, it does not matter whether one agrees with Randall's claim that it is subjective costs which determine recreation decisions — if researchers use cost estimates which are poor approximations to true costs, whatever they may be, then final welfare estimates may also be poor approximations to true welfare. Yet it is 
difficult to determine, a priori, just how poor the welfare approximations may be. Researchers undertaking applied travel cost studies face a vast array of implementation decisions. Not only must they choose from a range of different models (for example, the individual TCM, the hedonic TCM, the zonal TCM), but they must also make decisions regarding an appropriate estimation procedure, an appropriate functional form for the visitation equation, an appropriate set of variables to include within that equation, etc. Clearly, there are many ways in which to implement a given travel cost study, and errors in determining the behaviourally relevant price of travel will interact with other implementation decisions.

No single piece of work can hope to investigate all possible permutations of the problem. The purpose of this paper is to make a start in considering the quantitative significance of Randall's Difficulty by setting it in the cleanest and simplest possible context — ignoring most of the specification, measurement and estimation issues that are extensively discussed in the TCM literature. ${ }^{2}$ We use a linear model, where Ordinary Least Squares (OLS) regression is — Randall's Difficulty aside — an appropriate estimation technique. This allows us to focus on three main issues:

a) What conditions must be met for the TCM to generate ordinally measurable welfare estimates?

b) How sensitive are consumer surplus (CS) estimates to variations in researcher-assigned travel cost estimates? $?^{3}$ 
c) What are the prospects for solving, or circumventing, Randall's Difficulty?

The paper is organised as follows. In the next section we formulate Randall's Difficulty as an estimation problem and consider Randall's claim that, provided a single convention for assigning researcher-assessed costs is adhered to in all applications, the TCM generates ordinally valid welfare estimates. In section 3 we report some results from a survey that illustrate the differences between researcher-assigned costs and perceived costs. In section 4 we describe some Monte Carlo experiments which demonstrate the potential magnitude of the problem in terms of welfare estimates. In section 5 we discuss the prospects for dealing with Randall's Difficulty, and in section 6 we offer some concluding comments.

\section{Randall's Difficulty as an estimation problem}

In this section we abstract from many of the complexities of actual surveys so as to focus on the essence of Randall's Difficulty in the simplest possible context. Initially we assume that

- the expectation of subjective price per unit distance is the same for all visitors

- subjective costs determine recreation behaviour.

Then, for the simple linear case in which visits depend only on travel cost with population constant across locations, we have 


$$
\mathrm{V}_{\mathrm{i}}=\alpha+\beta \mathrm{P}_{\mathrm{i}}+\varepsilon_{\mathrm{i}}: \varepsilon_{\mathrm{i}} \sim \mathrm{NID}\left(0, \sigma_{\varepsilon}^{2}\right)
$$

and

$$
\mathrm{CS}=-(1 / 2 \beta) \Sigma_{\mathrm{i}} \mathrm{V}_{\mathrm{i}}^{2}
$$

where:

$\mathrm{V}_{\mathrm{i}}$ is visits from location $\mathrm{i}$

$D_{i}$ is distance to the site from location $\mathrm{i}$

$\mathrm{p}_{\mathrm{i}}=\mathrm{p}+\mu_{\mathrm{i}}$ is the (subjective) price per unit distance for location $\mathrm{i}$,

$$
\text { with } \mu_{\mathrm{i}} \sim \mathrm{NID}\left(0, \sigma_{\mu}{ }^{2}\right)
$$

$\mathrm{P}_{\mathrm{i}}=\left(\mathrm{p}+\mu_{\mathrm{i}}\right) \mathrm{D}_{\mathrm{i}}$ is the (subjective) cost of a visit from location $\mathrm{i}$

CS is consumers' surplus

We also assume that with $\mathrm{P}_{\mathrm{i}}$ unobservable, the analyst assigns the same cost per unit distance to all visitors:

$$
\begin{aligned}
& \mathrm{c}_{\mathrm{i}}=\mathrm{c} \text { is the (researcher assigned) cost per unit distance of a visit from } \\
& \text { location } \mathrm{i} \\
& \mathrm{C}_{\mathrm{i}}=\mathrm{cD}_{\mathrm{i}} \text { is the (researcher assigned) cost of a visit from location } \mathrm{i}
\end{aligned}
$$

The researcher regresses $V_{i}$ on $C_{i}$, which with $P_{i}=\left(p+\mu_{i}\right) D_{i}$ and $C_{i}=c D_{i}$ is:

$$
\begin{aligned}
\mathrm{V}_{\mathrm{i}} & =\alpha+\beta \mathrm{C}_{\mathrm{i}}+\varepsilon_{\mathrm{i}} \\
& =\alpha+\beta\left(\left[\mathrm{p}+\mu_{\mathrm{i}}\right] / \mathrm{c}\right) \mathrm{C}_{\mathrm{i}}+\varepsilon_{\mathrm{i}}
\end{aligned}
$$


which can be written as a, special, random coefficient model:

$$
\mathrm{V}_{\mathrm{i}}=\alpha+B_{i} \mathrm{C}_{\mathrm{i}}+\varepsilon_{\mathrm{i}}: \quad B_{i} \sim \mathrm{N}\left([\beta(\mathrm{p} / \mathrm{c})], \sigma_{\mu}{ }^{2} / \mathrm{c}\right)
$$

OLS regression of $\mathrm{V}_{\mathrm{i}}$ on $\mathrm{C}_{\mathrm{i}}$ will yield an unbiased estimate for the expected value of $B_{i}$, $\beta(\mathrm{p} / \mathrm{c})$. Clearly, unless $\mathrm{p}=\mathrm{c}$, the estimation of $\beta$ is biased. The bias will not vanish asymptotically.

TCM analysts generally estimate CS in one of two ways, using in (2) either actual visits $\left(\mathrm{V}_{\mathrm{i}}\right)$, or predicted visits (calculated from the fitted trip generating equation obtained by regressing $\mathrm{V}_{\mathrm{i}}$ on $\mathrm{C}_{\mathrm{i}}$ ). Denote the first consumers' surplus estimate $\mathrm{CS}_{\mathrm{a}}$ and the second $\mathrm{CS}_{\mathrm{e}}$. If we use the expected values for the intercept and slope estimates from an OLS regression of $\mathrm{V}_{\mathrm{i}}$ on $\mathrm{C}_{\mathrm{i}}$, with the actual $\mathrm{V}_{\mathrm{i}}$, we get

$$
\mathrm{CS}_{\mathrm{a}}=(\mathrm{c} / \mathrm{p}) \mathrm{CS}
$$

or

$$
\left(\mathrm{CS}-\mathrm{CS}_{\mathrm{a}}\right)=[1-(\mathrm{c} / \mathrm{p})] \mathrm{CS}
$$

for the error arising in estimating consumers' surplus. No such neat result holds for $\mathrm{CS}_{\mathrm{e}}$ - the expression for $\left(\mathrm{CS}-\mathrm{CS}_{\mathrm{e}}\right)$ is $\left(\mathrm{CS}-\mathrm{CS}_{\mathrm{a}}\right)$ plus one positive term and minus two positive terms, where the terms involve $\mathrm{p}^{2}, \beta^{2}, \Sigma \varepsilon_{\mathrm{i}}^{2} \Sigma \mu_{\mathrm{i}}^{2} \mathrm{D}_{\mathrm{i}}^{2}$, and $\Sigma \mathrm{D}_{\mathrm{i}}^{2}$. Generally, this expression may be less than or greater than $\left(\mathrm{CS}-\mathrm{CS}_{\mathrm{a}}\right)$. Either way, the TCM will not yield welfare estimates that are valid cardinally unless $\mathrm{c}=\mathrm{p}$. Note, this analysis 
differs from that of Englin and Shonkwiler (1995) who identify Randall's Difficulty with the standard econometric problem of measurement error for an explanatory variable, in this case travel cost. They state that an implication is that 'the parameters ....are attenuated' so that 'the estimated slope of the demand curve will be too flat' leading to 'higher estimates of consumer surplus than is true'. This contrasts with the results presented here where higher and lower consumer surplus estimates are obtained according to the convention used for measuring travel costs. The difference arises because Englin and Shonkwiler assume the standard sort of measurement error with, in our notation, $\mathrm{c}_{\mathrm{i}}=\mathrm{p}_{\mathrm{i}}+\xi_{\mathrm{i}}$ where $\xi_{\mathrm{i}}$ has zero expectation.

Randall argues that while cardinal welfare measurement is impossible, TCM using observer-assessed costs can support ordinal measurement. By this he means that, provided the same unit cost assessment conventions are followed at each site, TCM will rank sites correctly in welfare terms ${ }^{4}$. However, formulating Randall's Difficulty as an estimation problem indicates that the order-preserving conditions are more complex than simple convention consistency.

Consider two sites 1 and 2, where consumers' surplus is larger at the latter, so that $\mathrm{CS}_{2}=\mathrm{kCS}_{1}, \mathrm{k}>1$. Now, leaving aside sampling effects, consider estimates for consumers' surplus at each site based on using actual, rather than predicted, visits. From (5) these are $\mathrm{CS}_{\mathrm{a} 1}=\left(\mathrm{c}_{1} / \mathrm{p}_{1}\right) \mathrm{S}_{1}$ and $\mathrm{CS}_{\mathrm{a} 2}=\left(\mathrm{c}_{2} / \mathrm{p}_{2}\right) \mathrm{S}_{2}$ so that $\mathrm{CS}_{\mathrm{a} 2} / \mathrm{CS}_{\mathrm{a} 1}>1$ requires

$$
\left(\mathrm{c}_{2} / \mathrm{c}_{1}\right)>\left(\mathrm{p}_{2} / \mathrm{p}_{1}\right) /(1 / \mathrm{k})
$$


and $c_{2}=c_{1}$ alone is neither necessary nor sufficient. If $\mathrm{p}_{1}=\mathrm{p}_{2}$, then $\mathrm{c}_{2} / \mathrm{c}_{1}>1 / \mathrm{k}$ is necessary and sufficient, and is satisfied for $\mathrm{c}_{2}=\mathrm{c}_{1}$, given $\mathrm{k}>1$. If $\mathrm{c}_{2}=\mathrm{c}_{1}$ then (7) becomes

$$
\left(\mathrm{p}_{1} / \mathrm{p}_{2}\right)>1 / \mathrm{k}
$$

where $\mathrm{p}_{1}=\mathrm{p}_{2}$ is sufficient but not necessary.

In words, this demonstrates that convention consistency will be order preserving if the expectation of perceived unit travel price is the same across sites (although convention consistency is not necessary for order-preservation). If the expectation of perceived unit travel price differs across sites, then convention consistency is neither necessary nor sufficient for order-preservation.

Should it generally be assumed that perceived unit travel price is the same across sites? As far as we are aware, the published literature does not offer any evidence that bears directly upon this question. We now consider the data from the Tidbinbilla survey.

\section{The Tidbinbilla Survey}

Tidbinbilla is a nature reserve in the Australian Capital Territory (ACT). It is visited by residents of the ACT, by residents of Queanbeyan (a city in New South Wales contiguous with Canberra), and by people visiting Canberra and Queanbeyan. The 
reserve comprises 5515 hectares of rolling hills and steep mountain slopes, with numerous valleys and small creeks. It contains a broad cross-section of Australian forest and grassland types. Some of the area was previously farmed, but there is no farming now. The nature reserve itself is home to abundant native wildlife: there are over 150 species of native birds. Within the nature reserve there are large enclosed areas where kangaroos and koalas can be observed, and wetlands with bird watching facilities. Kangaroos, and emus, are also present in the unenclosed area of the nature reserve. Access to the enclosures and hides is from carparks adjacent to paved roads: off-road use of motor vehicles is prohibited. The ACT Parks and Conservation Service manages Tidbinbilla.

In 1994, one of the authors conducted a visitor survey at Tidbinbilla, as the basis for an undergraduate thesis at the Australian National University (Bull 1994). Eight hundred visitors either completed and returned a questionnaire, or were interviewed using the questionnaire. Surveying took place during two parts of the year, corresponding to peak and off-peak visitation periods, as determined from visitor number records kept by the ACT Parks and Conservation Service.

Respondents were asked to provide information on: their sex (SEX), their age (AGE), their educational status (EDU), their employment status (EMP), their income (INC), the number of adults (ADS) in their party, the number of children (KIDS) in their party, the length of their stay at Tidbinbilla (STAY), whether this was their first visit to Tidbinbilla (FIRST), and whether their trip from their point of departure involved visiting other destinations. Additional information (added by the researcher) 
included: whether the visit was made during peak periods (PEAK), and whether the questionnaire had been completed by the respondent or by an interviewer (INTVW).

Respondents were also asked to provide information relating to subjective and researcher-assessed travel costs, including: their perception of the time taken for the one-way trip (TIME), their perception of the one-way transport cost of the visit ${ }^{5}(\mathrm{P})$, their point of departure for the visit, their place of residence, their travel model, and the make and model of their motor vehicle. This information was used to calculate ${ }^{6}$ :

D - the one-way distance travelled from their point of departure to Tidbinbilla, $\mathrm{p}=\mathrm{P} / \mathrm{D}-$ the perceived unit price of travel,

$\mathrm{c}_{1}$ - the fuel cost per kilometre for the make and model of vehicle,

$\mathrm{c}_{2}$ - the total cost per kilometre for the make and model of vehicle, SPEED = D/TIME.

It was not possible to calculate $c_{1}$ and $c_{2}$ when travel mode was other than motor vehicle or when respondents did not provide complete information on the make and model of their motor vehicle. These observations were, therefore, deleted.

Observations were also deleted where the departure point was other than Canberra or Queanbeyan and where there were destinations additional to Tidbinbilla. The final data set contained information on 410 visitor groups.

Our researcher-defined estimates of per-kilometre travel costs $\left(c_{1}\right.$ and $\left.c_{2}\right)$ may appear somewhat simplistic in comparison to some other studies. We have not, for example, 
addressed the problem of multiple-site visitors (choosing to exclude them from the data set, rather than attempting to allocate their joint travel costs). Similarly, we have not attempted to allow for the opportunity cost of time, and we do not include expenditures on site (in 1994 opportunities for on-site expenditure at Tidbinbilla were limited to a small information centre at the entrance selling a limited range of postcards and posters). This does not affect the basic analysis, which could be replicated with a broader range of cost categories without affecting the nature of the results. We return to this point in our discussion of the Monte Carlo simulations in the next section.

The perceived unit cost of travel varied widely across respondents. We regressed $\mathrm{p}$ on each of $c_{1}$ and $c_{2}$, together with D, TIME, FIRST, PEAK, INTVW, ADS, KIDS, INC, EMP, EDU, AGE, SEX, and STAY. Based on significance levels, variables were dropped and the equations re-estimated. We do not report any results for the equations involving $c_{2}$ as in no case did the $t$ value on its coefficient estimate exceed 0.6. The final result for the $\mathrm{c}_{1}$ variant $^{7}$ was, $\mathrm{t}$ values in parenthesis,

$$
\begin{aligned}
& \mathrm{p}=30.36+2.07 \mathrm{c}_{1}-0.70 \mathrm{D}+0.18 \mathrm{TIME}+9.54 \mathrm{FIRST}+4.55 \mathrm{PEAK}-1.43 \mathrm{EMP} \\
& \begin{array}{lllll}
(3.89) & (2.87) & (5.15) & (2.01) & (3.03)
\end{array} \\
& \mathrm{R}^{2} \text { (adjusted) }=0.1044
\end{aligned}
$$

These results are consistent with the hypothesis that perceived travel price varies across sites; sites differ in regard to the profile of visitors by EMP, FIRST and PEAK, and in D and TIME, and these are significant determinants of the perceived price of travel. As noted in the previous section, if the expectation of perceived unit travel 
price differs across sites, then convention consistency does not guarantee that the TCM will be able to generate welfare estimates that are valid ordinally.

These results show perceived unit travel price falling with distance. ${ }^{8}$ The implications of this for the question of the order-preserving property of convention consistency, discussed above, are of interest. Suppose, for example, that the expectation for perceived travel price is constant for a given site, but that there are two sites at different distances from the population of interest and that the expectation of $\mathrm{p}_{\mathrm{i}}$ is lower at the more distant site. ${ }^{9}$ Suppose also that $\mathrm{CS}_{2}=\mathrm{kCS}_{1}, \mathrm{k}>1$, and that $\mathrm{CS}_{2}$ is the more distant site with $\mathrm{p}_{2}\left\langle\mathrm{p}_{1}\right.$. Then, from(7), the order preserving condition is $\mathrm{c}_{2} / \mathrm{c}_{1}>$ $\left(\mathrm{p}_{2} / \mathrm{p}_{1}\right)(1 / \mathrm{k})$ where $\mathrm{p}_{2} / \mathrm{p}_{1}<1$ and $\mathrm{p}_{2} / \mathrm{p}_{1}<1$, so that for convention consistency, $\mathrm{c}_{1}=\mathrm{c}_{2}$, the condition will be satisfied. If, on the other hand, the site with the larger consumers' surplus is the nearer one, so that $\mathrm{p}_{2}>\mathrm{p}_{1}$, then the condition is $\mathrm{c}_{2} / \mathrm{c}_{1}>\left(\mathrm{p}_{2} / \mathrm{p}_{1}\right)(1 / \mathrm{k})$ where $\mathrm{p}_{2} / \mathrm{p}_{1}>1$ and $1 / \mathrm{k}<1$ so that satisfaction of the order preserving condition is not guaranteed by convention consistency.

\section{The empirical significance of Randall's Difficulty}

The data described in section 3 were used in the popular zonal averaging implementation of the TCM. We treated suburbs (and Queanbeyan) from which the survey recorded visitors as zones, giving 80 zones (there were three suburbs for which no visitors were recorded). We defined the dependent variable as respondents per $z e^{10}$ and the travel cost variable as the average of the travel costs for the respondents in a zone. We considered other, zonal average, variables from the list reported in 
section 3 as possible explanatory variables in specifications with both visits per thousand of population and visits as dependent variable, but none appeared with a significant coefficient in any specification. Given the truncated nature of the survey data, we also estimated trip-generating equations according to the TOBIT model, using LIMDEP. The results so obtained were trivially different from those obtained using OLS, the results from which are shown below ( $\mathrm{t}$ ratios shown in brackets):

$$
\begin{aligned}
& \mathrm{V}=4.0094-0.0008 \mathrm{P}+0.0007 \mathrm{Pop} \\
& \begin{array}{lll}
(4.44) \quad(-2.13) \quad(5.96)
\end{array} \\
& \mathrm{R}^{2} \text { (adjusted) }=0.3219 \\
& \mathrm{~V}=7.1619-0.0072 \mathrm{C}_{1}+0.0006 \mathrm{Pop} \\
& \text { (4.71) (-3.08) (5.44) } \\
& \mathrm{R}^{2} \text { (adjusted) }=0.3606 \\
& V=6.7384-0.0011 C_{2}+0.0006 \text { Pop } \\
& \text { (5.14) (-3.53) (5.72) } \\
& \mathrm{R}^{2} \text { (adjusted) }=0.3820
\end{aligned}
$$

TCM practitioners will point to a number of problems, widely discussed in the literature, potentially attending the above results. We comment briefly on some of these below.

First, no allowance has been made for the presence of substitute sites. As noted by McKean and Revier (1990, p 435), researchers who decide to exclude measures of 
other sites may not be able to anticipate either the magnitude or the direction of the resultant omitted variable bias. In the case of Tidbinbilla there are good reasons for supposing (see Common et al 1997) that the assumption of no close substitutes for the visitor population is reasonable. There does not appear, in any case, to be a reason for believing that an omitted variable bias would operate differently across (9), (10) and (11). We are primarily interested in the relative sizes of the coefficients on the different measures of travel costs.

Second, it may have been more appropriate to use an individual TCM specification. We could have used one, but data were collected only from a sample of visitors giving rise to the dual problems of truncation and endogenous stratification. Noting that "...there is no guarantee that the statistically more complex models based on individual data (which are capable of allowing for truncation and endogenous stratification) will outperform the relatively simple, aggregate bias prone zonal models" (Hellerstein 1992, p. 2004), we chose the most popular zonal specification. Again, we note that our primary interest is in the relative sizes of the coefficients on different measures of travel cost; there is no reason for believing that the coefficients would differ if using a zonal TCM yet would remain the same if using an individual specification.

Third, as pointed out by one of our referees, there is some question as to whether it is appropriate to use the TCM for essentially 'local' parks. It is argued that a problem arises if distance costs are small relative to other factors that influence recreation behaviour. In each of the above regressions, the coefficients on travel costs are 
statistically significant and correctly signed. For our, limited comparative, purposes, that is enough.

Fourth, we have excluded all zero-visit zones from the analysis. This is a widely adopted ad hoc means of dealing with a problem for which theory provides no clear answer (see Smith 1989, p. 286). Again, we note that there is no reason to suppose that following some other procedure would have produced different differentials across the alternative measures of travel cost.

Finally, given our primary interest (in differentials across alternative measures of travel cost), we report only estimated linear equations. This avoids the somewhat vexed question of choice of functional form for fitted trip generating equations (see Kerr and Sharp 1985, p. 130).

For any given set of choices about other aspects of TCM implementation, different choices about the measurement of travel costs must affect estimates of the response of visitation to travel costs. English and Bowker (1996, p 90), who also consider alternative functional forms for the trip generating equations, conclude that "the selection of travel cost prices is as important in estimating consumer surplus as is choice of functional form". The results reported as (9), (10) and (11) show that the estimated response of visitation to travel cost variation can vary by an order of magnitude according to the convention adopted for travel cost measurement. Going from researcher-assigned full costs $\left(C_{2}\right)$ to researcher-assigned fuel cost $\left(C_{1}\right)$ increases the absolute size of the estimated coefficient by a factor of seven. The ratio of the estimated coefficient using $\mathrm{C}_{1}$ to that using respondents' perceived costs $(\mathrm{P})$ is 8.75 . 
We now consider the results from some Monte Carlo simulations, using them to consider the implications of using different travel cost measurement conventions for the estimation of consumers' surplus. There are several reasons for adopting this approach. First, it enables us to examine the influence of the stochastic variables' variances, and the extent of the inefficiency apparent in (4), in comparison with the effect of using $\mathrm{c}$ rather than $\mathrm{p}$. Second, it is the only way to generate and report information on the sizes of $\mathrm{CS}_{\mathrm{e}}$ in relation to $\mathrm{CS}_{\mathrm{a}}$ (as discussed in section 2 above). Third, it could be the only way to generate results for more complex specifications of the context for Randall's Difficulty - particularly for small sample properties. Using it for the present case will permit comparison across it and more complex cases.

Corresponding to (1), we generate data ${ }^{11}$ using

$$
\mathrm{V}_{\mathrm{i}}=4-0.001 \mathrm{P}_{\mathrm{i}}+\varepsilon_{\mathrm{i}}: \varepsilon_{\mathrm{i}} \sim \mathrm{N}\left(0, \sigma_{\varepsilon}^{2}\right)
$$

where

$$
\mathrm{P}_{\mathrm{i}}=\left(20+\mu_{\mathrm{i}}\right) \mathrm{D}_{\mathrm{i}}: \mu_{\mathrm{i}} \sim \mathrm{N}\left(0, \sigma_{\mu}^{2}\right)
$$

The starting values for the intercept and slope parameters in (12) were chosen so as to approximate those in (9). The ranges used for the variances of $\mu_{\mathrm{i}}$ and $\varepsilon_{\mathrm{i}}$ were chosen to ensure that (12) does not generate negative visits. The experiment assumes that researchers can observe $V_{i}$ and $D_{i}$, but are unable to observe $P_{i}$. Two different observer-assessed unit distance costs are used: 


$$
\mathrm{C}_{1 \mathrm{i}}=10 \mathrm{D}_{\mathrm{i}}
$$

and

$$
\mathrm{C}_{2 \mathrm{i}}=50 \mathrm{D}_{\mathrm{i}}
$$

These parameter values of 10 and 50 respectively approximate the mean values of $c_{1}$ and $c_{2}$. The results reported are based on 50 replications. In each, $V_{i}$ observations are generated by (12), with $\mathrm{D}_{\mathrm{i}}=\mathrm{i}$ for $\mathrm{i}=1,2 \ldots . .80$, and $\mathrm{V}_{\mathrm{i}}$ is regressed on $\mathrm{C}_{\mathrm{i}}$ generated according to (13) and (14) respectively. In each replication the estimated slope and intercept coefficients are used to calculate estimates of consumers' surplus using actual and predicted visits, and actual consumers' surplus is also calculated using the $\mathrm{V}_{\mathrm{i}}$ generated by (12).

Table 1 shows the mean estimated slope coefficient (across the 50 replications) for selected values for the variances of $\mu_{\mathrm{i}}$ and $\varepsilon_{\mathrm{i}}$ for $\mathrm{c}=10$. Table 2 shows the same information for $\mathrm{c}=50$. Two points are readily apparent. First, the reported means accord closely to the results at (3) and (4) above on substitution for $\beta, \mathrm{p}$ and c. Second, there is no pattern of dependence on the values taken by the variances for $\mu_{\mathrm{i}}$ and $\varepsilon_{\mathrm{i}}$ (although the variances of the slope estimates across replications do depend on these values, increasing with $\sigma_{\mu}{ }^{2}$ and $\sigma_{\varepsilon}{ }^{2}$ ). For given values of $\sigma_{\mu}{ }^{2}$ and $\sigma_{\varepsilon}{ }^{2}$ the variance is larger for $c=10$ than for $c=50$, which is consistent with (3) and (4). ${ }^{12}$ As originally stated by Randall, his difficulty relates to the use of observer-assessed travel costs for estimating welfare measures. Tables 3 and 4 report results for consumers' surplus, where CS is the mean for the actual consumers' surplus, $\mathrm{CS}_{\mathrm{a}}$ is the 
mean when consumers' surplus is calculated using the estimated regression coefficients with actual visits, and $\mathrm{CS}_{\mathrm{e}}$ is the mean when using visits predicted by the fitted equation. Expected consumers' surplus is $\$ 416,000$. Where $\mathrm{c}=10$ is used, $\mathrm{CS}_{\mathrm{a}}$ is always approximately 50 per cent of CS: where $\mathrm{c}=50$ is used $\mathrm{CS}_{\mathrm{a}}$ is always approximately 2.5 times CS.

For this experiment, Tables 3 and 4 show that $\mathrm{CS}_{\mathrm{e}}$ is always $\leq \mathrm{CS}_{\mathrm{a}}$, but the difference between $\mathrm{CS}_{\mathrm{e}}$ and $\mathrm{CS}_{\mathrm{a}}$ is always considerably less than the difference between $\mathrm{CS}_{\mathrm{e}}$ and CS. That is, consumer surplus estimates differ according to whether observed or predicted levels of visitation are used in the calculations, but these differences are relatively insignificant when compared to differences generated by alternative conventions for cost measurement.

We also find that the variance on $\mathrm{CS}_{\mathrm{a}}$ (across replications) is always greater than that on CS, and always at least as great as that on $\mathrm{CS}_{\mathrm{e}}$. The variance for each of $\mathrm{CS}, \mathrm{CS}_{\mathrm{a}}$ and $\mathrm{CS}_{\mathrm{e}}$ is greater for $\mathrm{c}=50$, than for $\mathrm{c}=10$. For $\mathrm{CS}_{\mathrm{a}}$ with $\mathrm{c}=50$, the variance ranges from $1.97 \times 10^{8}\left(\sigma_{\mu}^{2}=1, \sigma_{\varepsilon}^{2}=0\right)$ to $3.58 \times 10^{10}\left(\sigma_{\mu}^{2}=25, \sigma_{\varepsilon}^{2}=0.25\right)$ : with $\mathrm{c}=10$, it ranges from $9.48 \times 10^{6}\left(\sigma_{\mu}{ }^{2}=1, \sigma_{\varepsilon}{ }^{2}=0\right)$ to $1.26 \times 10^{9}\left(\sigma_{\mu}{ }^{2}=25, \sigma_{\varepsilon}{ }^{2}=0.25\right){ }^{13}$

These results generate the $V_{i}$ data with (12) - an approximation to the trip generating equation, estimated from the Tidbinbilla data using perceived costs (9). This locates the results in the context of an actual TCM implementation. As noted above, it could be argued that this implementation is subject to problems such that the estimates in (9) are biased with respect to some true parameter values for visitation at Tidbinbilla. In 
any case, it would be of interest to know whether the results reported in Tables 1 through 4 are sensitive to the parameter values used. We therefore conducted further simulations using other starting parameter values for (12). In all cases, the general pattern of results remained the same.

We also note that for the Tidbinbilla survey data, unit travel costs varied across respondents whereas this specification has researcher-assessed unit travel cost $\left(\mathrm{c}_{1}\right.$ and $\mathrm{c}_{2}$ ) as a constant across locations. We therefore investigated a specification in which the researcher assessed unit travel cost is a normally distributed random variable with expectation c. In this case, corresponding to (4) we get a random coefficient model in which $B_{\mathrm{i}}$ and $\mathrm{C}_{\mathrm{i}}$ are not statistically independent, so that OLS would not yield an unbiased estimate of the expectation of $B_{i}$. The results for the slope coefficient are that stochasticity in researcher-assessed unit cost reduces the estimated size, moving it toward $\mathrm{p}$ for the $\mathrm{c}_{1}$ case and away from $\mathrm{p}$ for the $\mathrm{c}_{2}$ case. However, the effects are small compared with those due to differences between $c_{1}, c_{2}$ and $p$, reported above. This is also the case in regard to the estimation of consumers' surplus. ${ }^{14}$

These results suggest that Randall's Difficulty should not be dismissed as a theoretical nicety of no empirical significance, but may well have serious implications for the social decision making that the TCM is supposed to inform. To make this point apparent, consider the following. Suppose that a recreational area is the site for a project for which the net present value, leaving aside the impact on recreational value, is $B_{d}-C_{d}$, and suppose that going ahead with the project would mean that recreational benefits went to zero. Let $\mathrm{X}$ represent the present value of the lost recreational benefits evaluated on the basis of perceived travel price. Then, from the results above, 
evaluation using $c_{1}=2.5 p$ would give $\mathrm{CS}_{\mathrm{a} 1}=2.5 \mathrm{X}$, while using $\mathrm{c}_{2}=0.5 \mathrm{p}$ would give $\mathrm{CS}_{\mathrm{a} 2}=0.5 \mathrm{X}$. If the proper basis for social decision making is $\mathrm{p}$, four cases can be distinguished:

A. $B_{d}-C_{d}<0.5 X$ : The project should not go ahead. This will be the decision whichever cost convention is used.

B. $0.5 \mathrm{X}<\mathrm{B}_{\mathrm{d}}-\mathrm{C}_{\mathrm{d}}<\mathrm{X}$ : The project should not go ahead. The decision will be to go ahead if $c_{2}$ is used, and not to go ahead if $c_{1}$ is used.

C. $\mathrm{X}<\mathrm{B}_{\mathrm{d}}-\mathrm{C}_{\mathrm{d}}<2.5 \mathrm{X}$ : The project should go ahead. The decision will be to go ahead if $c_{1}$ is used, and not to go ahead if $c_{2}$ is used.

D. $B_{d}-C_{d}>2.5 X$ : The project should go ahead. This will be the decision whichever cost convention is used.

If it is taken that $c_{1}$ is the proper basis for social decision making, then the cases are:

E. $B_{d}-C_{d}<0.5 X$ : The project should not go ahead. This will be the decision whichever convention is used.

F. $0.5 \mathrm{X}<\mathrm{B}_{\mathrm{d}}-\mathrm{C}_{\mathrm{d}}<\mathrm{X}$ : The project should not go ahead. The decision will be to go ahead if $c_{2}$ is used, but not to go ahead if $c_{1}$ is used. 
G. $\mathrm{X}<\mathrm{B}_{\mathrm{d}}-\mathrm{C}_{\mathrm{d}}<2.5 \mathrm{X}$ : The project should not go ahead. The decision will be to go ahead if $c_{2}$ is used, but not to go ahead if $c_{1}$ is used.

H. $B_{d}-C_{d}>2.5 X$ : The project should go ahead. This will be the decision whichever convention is used.

The dollar value of the band widths here depend on the value of $\mathrm{X}$, which depends on the per-trip consumers' surplus as estimated, the annual number of trips in the population, the length of time for which it is assumed that recreation benefit is lost, and the discount rate. Clearly, in some applications the bands could be wide, and, depending on the size of $B_{d}-C_{d}$, use of the incorrect cost convention could lead to large social losses. ${ }^{15}$

\section{Is there a solution to the Difficulty?}

Randall's Difficulty with the TCM arises if a) it is accepted that perceived travel costs are the appropriate cost measure, and b) only observer-assessed unit travel costs are available.

Randall (1994) clearly accepts (b) as binding, suggesting, in general terms, two conceivable solutions, neither of which involves collecting respondent data on perceived costs. However, TCM practitioners could ask respondents for their assessment of travel expenditure, as was done in the Tidbinbilla survey reported here. ${ }^{16}$ 
But the regression results reported in section 3 suggest that the answers to such questions could be of questionable usefulness as inputs to the TCM.

For example, the regression results show perceived vehicle unit distance price decreasing with distance but increasing with, self-assessed, time spent travelling. This does not accord with the fact that distance and time must, on average, be positively associated. Further, while it is generally agreed that travel cost should include the opportunity cost of time spent travelling, most travel cost research focuses on measuring the price rather than the quantity of travel time. Evidence from this survey suggests that recreationers are not necessarily better judges of that quantity than researchers. For example, the results in terms of SPEED imply that many respondents could not accurately recall how long the trip had taken them; the mean of SPEED was $63.92 \mathrm{kmph}$, with a standard deviation of 18.74 , a minimum of 10.33 and a maximum of 168. Note that from any origin considered in this data set the trip includes both urban and rural segments, and that the urban speed limit is, at most, $80 \mathrm{kmph}$, while the rural is $100 \mathrm{kmph}$.

It is, perhaps, at least partially for this reason that the explanatory power of (9) (where visits were defined as a function of perceived costs) is less than that of either (10) or (11) (where visits were defined as a function of researcher-defined costs). If (a) above is accepted, then one should investigate the coherence and consistency of respondent perceptions before using that data to generate welfare estimates. ${ }^{17}$ It is perhaps because of an implicit assumption about the usefulness of reported perceptions that Randall did not mention this solution, and relatively few TCM analysts have adopted it. 
Some might have a problem with Randall's insistence that what matters for TCM recreation site welfare assessment is perceived opportunity cost. It is generally understood that in CBA recreation site benefits are, at least implicitly, to be compared with other costs and benefits assessed on the basis of actual, market, prices where such exist, and on some other basis where they do not. If (a) above is accepted, consistency would appear to require that all prices used in CBA should be those perceived. Unless one believes that markets ensure the coincidence of actual and perceived prices and that other non-market valuation techniques also produce consistent perceived prices, the implied amount of effort required for CBA is very great. Certainly, the majority of welfare economists do not argue for analysis in terms of perceived prices and opportunity costs. On the other hand, if the use of perceived price is rejected, there remains the problem of deciding the basis on which to measure travel cost. As the results here show, even when attention is restricted to vehicle costs, the two available bases of measurement $\left(c_{1}\right.$ and $\left.c_{2}\right)$ can produce widely different welfare estimates with serious implications for the use of TCM to inform project appraisal.

Does considering Randall's Difficulty as an estimation problem suggest the nature of a solution based on observable behaviour? We sketch here the essentials of a possible approach. The insight behind TCM is that travel is a necessary input to the consumption of recreation site services. Suppose that there is some other necessary input, which has a unique market price per unit. Then, assuming a constant unit distance price, we could write

$$
\mathrm{V}_{\mathrm{i}}=\alpha+\beta_{1} \mathrm{p}_{1} \mathrm{D}_{\mathrm{i}}+\beta_{2} \mathrm{p}_{2} \mathrm{Z}_{\mathrm{i}}
$$


where $\mathrm{Z}$ is the other input with price $\mathrm{p}_{2}$, and $\mathrm{p}_{1}$ is the distance price. Suppose that we regress $V_{i}$ on $D_{i}$ and $Z_{i}$ with the result

$$
V_{i}=a+b_{1} D_{i}+b_{2} Z_{i}
$$

so that we have

$$
\mathrm{b}_{1}=\beta_{1} \mathrm{p}_{1}
$$

and

$$
\mathrm{b}_{2}=\beta_{2} \mathrm{p}_{2}
$$

From (17)

$$
\beta_{2}=b_{2} / p_{2}
$$

and if we assume that $\beta_{1}=\beta_{2}$, then from (16) we have

$$
\mathrm{p}_{1}=\mathrm{b}_{1} / \beta_{1}=\mathrm{b}_{1} / \beta_{2}=\mathrm{b}_{1} /\left(\mathrm{b}_{2} / \mathrm{p}_{2}\right)
$$

as an estimate of the unit distance price implied in observed behaviour, and we can use the derived estimate of $\beta_{1}=\beta_{2}$ to forecast rationing/revenue responses to entry price levels and to estimate consumers' surplus. The feasibility of this approach depends on the existence of the required commodity $Z$, and requires the assumption that $\beta_{1}=\beta_{2}$. The assumption that recreation consumption responds in the same way to variations in 
expenditures on two necessary inputs is, perhaps, acceptable. The real problem is finding a candidate for the role of $Z$. Unfortunately, at this time we have no suggestions in this regard.

This approach is a variant of that proposed in Common (1973) and McConnell and Strand (1981) for deriving the valuation of time implicit in observed recreational behaviour, rather than importing such valuation from other sources. The essential argument in those papers can be stated in terms of the above algebra if $Z_{\mathrm{i}}$ in (15) is treated as time spent travelling, and $\mathrm{p}_{1}$ as a given (and researcher assigned) unit distance cost, so that the behaviourally implicit value of time is estimated as:

$$
\mathrm{p}_{2}=\mathrm{b}_{2} /\left(\mathrm{b}_{1} / \mathrm{p}_{1}\right)
$$

Essentially the same idea is exploited in Englin and Shonkwiler (1995), using a latent variable specification of travel cost. Note that this approach resolves Randall's Difficulty only if it is assumed that $\mathrm{p}_{1}$ is equal to the perceived/subjective unit distance price of travel, and that distance and time are the only relevant sources of cost. Otherwise, the problem remains, as the estimate for $\mathrm{p}_{2}$ is conditioned on the value for $\mathrm{p}_{1}$.

\section{Concluding remarks}

Our results show that: 
a) The claim that TCM using observer-assessed distance cost can produce valid ordinal monetary welfare rankings holds only under more restrictive conditions than those stated by Randall.

b) Where costs are observer-assessed, the resulting welfare estimates are indeed artefacts of the cost accounting conventions adopted, and the implications for decision making may be substantial. ${ }^{18}$

c) Visitor responses to questions about the perceived price of travel may be incoherent and/or inconsistent.

As we have noted, there are numerous other problems attending implementation of the TCM which we have not dealt with here. Rather than mitigating Randall's Difficulty, they interact with it and are likely to compound $\mathrm{it}^{19}$. Unless and until the rather basic issues focussed on here can be resolved, results from TCM applications should be regarded sceptically. The reporting of any TCM results based on observer assessed cost should be accompanied by sensitivity analysis across, inter alia, alternative cost conventions. Where perceived prices are used, there should be some demonstration that responses to questions about the perceived price of travel are coherent and/or consistent.

The TCM is not, of course, the only research methodology employed by economists which generates results that should be interpreted with caution. In the particular context of environmental valuation, the contingent valuation method has been the subject of controversy. It has been criticised for reliance on hypothetical behaviour, 
while the TCM has been seen as having in its favour that it exploits data on observed behaviour. In fact, as Randall (1994) points out, the TCM does not rely entirely on observed behaviour. In the recreational context, we can observe quantity behaviour, but we cannot directly observe the price (s) to which that behaviour is responding. Our investigation suggests that, given this, it is premature to believe that the TCM produces more credible welfare estimates than alternative techniques. The nonobservability of travel price, Randall's Difficulty, is clearly of empirical significance as well as theoretical interest.

\section{Acknowledgements.}

We are grateful to two anonymous referees for useful comments and assert exclusive property rights to any remaining errors. 


\section{References}

Bateman, I. J., Garrod, G. D., Brainard, J. S. and Lovett, A. A. 1996, 'Measurement issues in the Travel Cost Method: a geographical information systems approach', Journal of Agricultural Economics, vol. 47, pp. 191-205.

Boxall, P. C., Adamowicz, W. L. and Tomasi, T. 1996, 'A nonparametric test of the traditional Travel Cost Model', Canadian Journal of Agricultural Economics, vol. 44, pp. 183-193.

Bull, T. 1994, Estimating Recreation Use Benefits: A Case Study of Tidbinbilla Nature Reserve, Undergraduate Thesis, Department of Economics, Australian National University, Canberra.

Common, M.,1973, 'A note on the use of the Clawson Method for the evaluation of recreation site benefits', Regional Studies, vol. 7, pp. 88-96.

Common, M., Bull, T. and Stoeck1 , N. 1997, 'The Travel Cost Method: an empirical investigation of Randall's difficulty', Working Paper in Ecological Economics No 9705, Australian National University, Canberra (available at http://cres.anu.edu.au/ dstern/anzsee/wp.html)

Englin, J. and Shonkwiler, J. S. 1995, 'Modelling recreation demand in the presence of unobservable travel cost: toward a Travel Price Model', Journal of Environmental Economics and Management, vol. 29, pp. 368-77.

English, D. B. K., and Bowker, J. M. 1996, 'Sensitivity of whitewater rafting consumer surplus to pecuniary travel cost specifications', Journal of environmental management, vol. 47, pp. 79 - 91.

Hanley, N. 1989, 'Valuing rural recreation benefits: an empirical comparison of two approaches', Journal of Agricultural Economics, vol. 40, pp. 361-74. 
Hellerstein, D. 1992, 'The treatment of nonparticipants in travel cost analysis and other demand models', Water Resources Research, vol. 28 (8), pp. 19992004.

Kerr, N. and Sharp, M. H. (eds) 1985, Valuing the Environment: Economic Theory and Applications, Centre for Resource Management, Lincoln College, N. Z.

Loomis, J., Creel, M. and Park, T. 1991, 'Comparing benefit estimates from Travel Cost and Contingent Valuation using confidence intervals for welfare measures', Applied Economics, vol. 23, pp. 1725-31.

McConnell, K. E. and Strand, I. 1981, 'Measuring the cost of time in recreation demand analysis: an application to sportfishing', American Journal of Agricultural Economics, vol. 63, pp. 153-156.

McKean, J. R., and Revier, C.F. 1990, 'An extension of "Omitted cross-price variable biases in the linear Travel Cost Model: correcting common misperceptions"”, Land Economics, vol. 66, pp. 430 - 436.

McKean, J. R., Johnson, D. M. and Walsh, R. G. 1995, 'Valuing time in Travel Cost demand analysis: an empirical investigation', Land Economics, vol. 71, pp. 96105.

McKean, J. R., Walsh, R. G. and Johnson, D. M. 1996, 'Closely related good prices in the Travel Cost Method', American Journal of Agricultural Economics, vol. 78, pp. 640-46.

NRMA 1994, What It Costs to Run Your Car, National Roads and Motorists Association, Sydney.

Randall, A. 1994, 'A difficulty with the Travel Cost Method', Land Economics, vol. 70, pp. 88-96. 
Smith, V. K., Desvousges, W. H. and Fisher, A. 1986 'A comparison of direct and indirect methods for estimating environmental benefits', American Journal of Agricultural Economics, vol. 68, pp. 280-90.

Smith, V. K. 1989, 'Taking stock of progress with Travel Cost Recreation Demand Methods: theory and implementation', Marine Resource Economics, vol. 6, pp. $279-330$.

Smith, V. K. and Kaoru, Y. 1990, 'Signals or noise? Explaining the variation in recreation benefit estimates', American Journal of Agricultural Economics, vol. 72, pp. 419-33.

Walsh, R. G. and Johnson, D. M. 1996, 'Closely related good prices in the Travel Cost Method', American Journal of Agricultural Economics, vol. 78, pp. 640-46. 
Table 1. Mean Estimates for Slope of Fitted Trip Generating Equation for $\mathbf{c}=10$.

$\begin{array}{lcccccc}\sigma_{\boldsymbol{\varepsilon}}{ }^{2} \Rightarrow & \mathbf{0} & \mathbf{0 . 0 1} & \mathbf{0 . 0 4} & \mathbf{0 . 0 9} & \mathbf{0 . 1 6} & \mathbf{0 . 2 5} \\ \sigma_{\mu}{ }^{2} & & & & & & \\ \Downarrow & & & & & & \\ \mathbf{0} & -0.00212 & -0.00199 & -0.00201 & -0.00199 & -0.00198 & -0.00202 \\ \mathbf{1} & -0.00200 & -0.00200 & -0.00198 & -0.00204 & -0.00201 & -0.00198 \\ \mathbf{4} & -0.00201 & -0.00201 & -0.00201 & -0.00197 & -0.00197 & -0.00194 \\ \mathbf{9} & -0.00200 & -0.00201 & -0.00198 & -0.00203 & -0.00197 & -0.00195 \\ \mathbf{1 6} & -0.00200 & -0.00200 & -0.00198 & -0.00198 & -0.00201 & -0.00198 \\ \mathbf{2 5} & -0.00201 & -0.00202 & -0.00202 & -0.00198 & -0.00200 & -0.00201\end{array}$

Table 2. Mean Estimates for Slope of Fitted Trip Generating Equation for $\mathrm{c}=50$

$\begin{array}{lllllll}\sigma_{\varepsilon}{ }^{2} \Rightarrow & 0 & 0.01 & 0.04 & 0.09 & 0.16 & 0.25\end{array}$

$$
\begin{array}{lllllll}
\sigma_{\mu}{ }^{2} & & & & & & \\
\Downarrow & -0.000400 & -0.000400 & -0.000399 & -0.000398 & -0.000391 & -0.000396 \\
\mathbf{0} & -0.000401 & -0.000399 & -0.000399 & -0.000404 & -0.000399 & -0.000395 \\
\mathbf{1} & -0.000400 & -0.000399 & -0.000399 & -0.000403 & -0.000396 & -0.000409 \\
\mathbf{4} & -0.000398 & -0.000397 & -0.000398 & -0.000392 & -0.000401 & -0.000406 \\
\mathbf{9} & -0.000399 & -0.000396 & -0.000398 & -0.000397 & -0.000397 & -0.000401 \\
\mathbf{1 6} & -0.000401 & -0.000399 & -0.000400 & -0.000395 & -0.000398 & -0.000415
\end{array}
$$


Table 3. Mean CS, CSa and CSe for $\mathrm{c}=10$ (\$, 000).

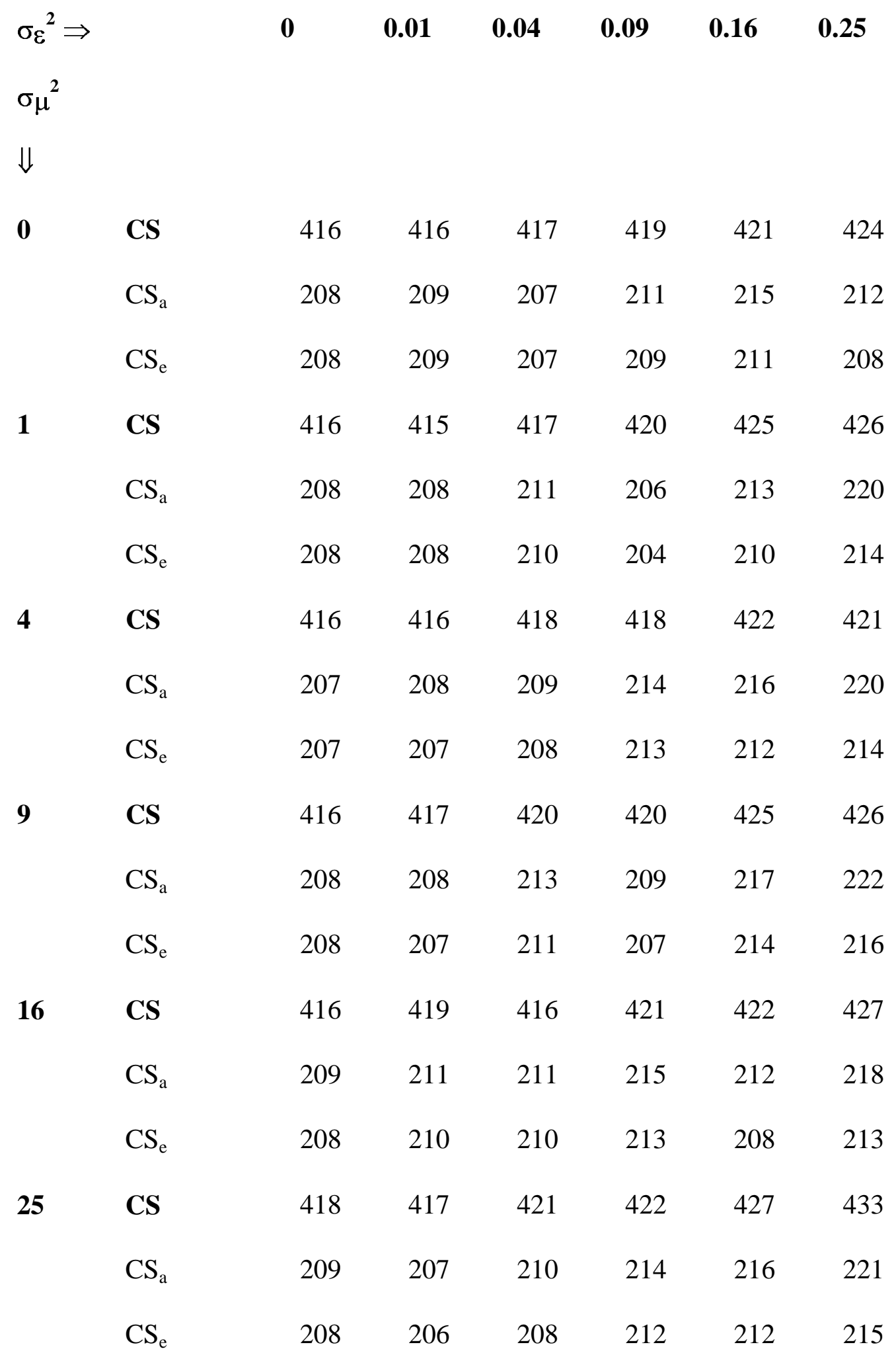


Table 4. Mean CS, CSa and CSe for $\mathrm{c}=50$ (\$ '000).

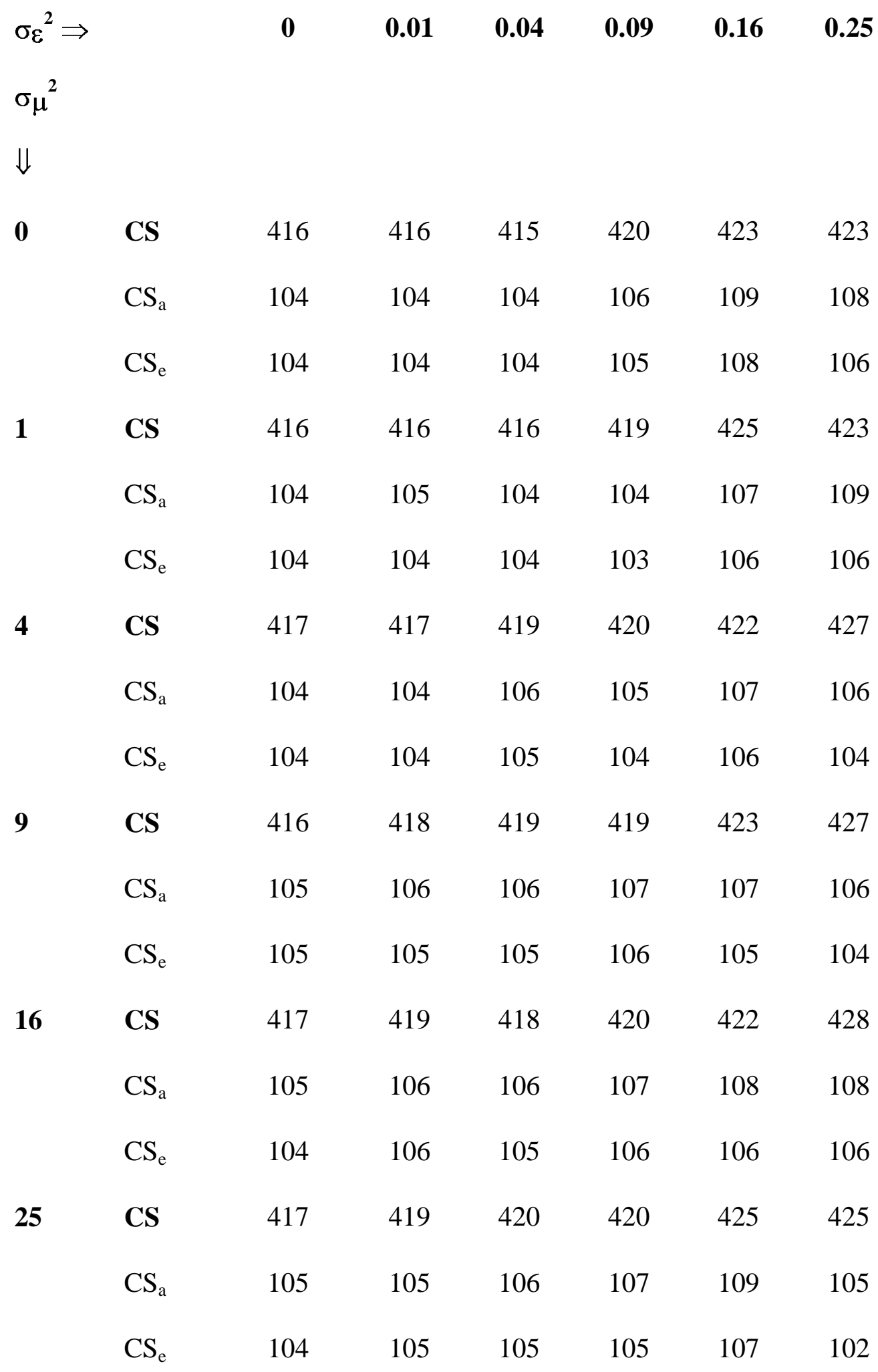


${ }^{1}$ In comparisons of TCM and CVM results for the same 'commodity' - see, for examples, Smith et al (1986), Hanley (1989), Loomis et al (1991) - it is usually taken that convergence confers credibility on the latter.

${ }^{2}$ See Randall (1994) or Common et al (1997), for an overview of the various problems.

${ }^{3}$ Interest in the TCM is not restricted to the production of 'welfare estimates'. It is also of interest in regard to using access pricing to ration use and/or raise revenue, although we do not consider those issues here. Further, while Randall considers welfare measures associated with (Hicksian) compensated demand functions, most TCM applications actually estimate the consumers' surplus associated with (Marshallian) uncompensated demand functions. In this paper, we consider consumers' surplus: the problems we discuss would also attend estimation of measures based on compensated demand functions.

${ }^{4}$ It is not usually envisaged that TCM results are intended only to rank sites. In some contexts, however, such a role may be of use, as for example where the question is which of a number of forest recreation sites should be used to supply timber, it being taken as given that the timber is to come from one of them.

${ }^{5}$ Respondents were asked: How much do you think the journey to Tidbinbilla has cost (i.e. one way expenses incurred in getting here such as petrol and 'wear and tear' on the car)?

${ }^{6} c_{1}$ and $c_{2}$ were taken from figures compiled by an Australian motoring organisation (NRMA 1994). D was measured from a large-scale map as the distance from the centre of the respondent's suburb to the entrance to the nature reserve. Measurement of D was relatively straightforward - since Canberra suburbs are unambiguously identified, known to residents, and are small in area and population size (average 4000 residents).

${ }^{7}$ In this case, coefficient estimates and t values were reasonably stable across alternative versions arising as variables were dropped.

${ }^{8}$ This has some intuitive plausibility. Note also that English and Bowker (1996) find self reported travel cost, excluding time cost, falling with distance.

9 The implications for estimation at a single site if $p_{i}$ declines with origin distance are also of interest, of course. Preliminary results from Monte Carlo experiments indicate that $\mathrm{p}_{\mathrm{i}}$ falling with distance introduces an additional source of bias in estimation of consumers surplus. This would further complicate ordinality conditions across sites.

${ }^{10}$ We note that in the zonal average implementation of the TCM it is usual, but not essential, to use visits per thousand of population as the dependent variable. For the Tidbinbilla data this produced unsatisfactory results, in that the coefficient on travel cost was typically not statistically significant at $10 \%$. However, as shown below, population is a significant explanatory variable and the estimated travel cost coefficients allow for its effect. The failure of the usual specification with visits per thousand as dependent variable here is interesting, but not for our purposes a major problem. A reviewer suggested that the explanation for the failure of the usual specification might be insufficient variation between zones in the number of visitors. However, this was not apparent from inspection of the raw data, and would anyway affect both specifications. Our results do give significant roles for both population and travel cost where these are entered as separate explanatory variables. It may be that for this site and population, and perhaps others, the usual specification of the role of population is a mis-specification. We note that with $C_{i}$ for zonal average travel cost

is

$$
\mathrm{V}_{\mathrm{i}} / \mathrm{Pop}_{\mathrm{i}}=\alpha-\beta \mathrm{C}_{\mathrm{i}}+\varepsilon_{\mathrm{i}}
$$

so that

$$
\mathrm{V}_{\mathrm{i}}=\alpha \mathrm{Pop}_{\mathrm{i}}-\beta \mathrm{C}_{\mathrm{i}} \mathrm{Pop}_{\mathrm{i}}+\varepsilon_{\mathrm{i}} \mathrm{Pop}_{\mathrm{i}}
$$

$$
\delta \mathrm{V}_{\mathrm{i}} / \delta \mathrm{C}_{\mathrm{i}}=\beta \mathrm{Pop}_{\mathrm{i}} \text { and } \delta \mathrm{V}_{\mathrm{i}} / \delta \mathrm{Pop}_{\mathrm{i}}=\alpha-\beta \mathrm{C}_{\mathrm{i}} .
$$

11 The programmes for these simulations were written in Basic: listings can be made available on request.

12 Full results for the variances, here and for consumers' surplus, are available on request.

13 These statements are not strictly true. For both stochastic term variances set to zero, the variance of $\mathrm{Sa}$ is 0 for $\mathrm{c}=10$ and $\mathrm{c}=50$.

14 The results for these experiments are available in Common et al (1997) 
${ }^{15}$ English and Bowker (1996) report per trip consumers' surplus estimates obtained using three different conventions for researcher assigned travel cost, and also using respondent reported costs. Six sets of results are reported for the latter, according to what is included and to how zones with no observations are treated. In no case are travel time costs included. Across the nine estimates for per trip consumers' surplus, the range is US\$21.32 to US\$140.62.

16 Papers in which respondents' assessments of travel expenditure are used include: Bateman et al (1996), McKean et al (1995), English and Bowker (1996), McKean et al (1996). In the McKean et al papers, distance was as reported by survey respondents, but travel time was 'based on reported distances and assume an average speed of 50 miles per hour'. English and Bowker find that consumer surplus per trip estimates differ substantially according to whether self-assessed or researcher assigned costs are used; see note 16. Unlike English and Bowker, Bateman et al include travel time cost in their travel cost measures, where the unit value of time spent travelling is inferred from the data according to goodness of fit criteria. Where researcher assigned vehicle cost is used, they find that the fuel cost convention ( with fuel cost per unit distance the same for all respondents), together with a unit time cost which is $2.5 \%$ of the wage rate (varying across respondents), gives the best fit. Using respondent assessed vehicle costs they find that the best fit is obtained by giving travel time zero value. They report that the overall fit of the two models is not significantly different. The former gives a household surplus estimate of $æ 3.95$, the latter œ4.53.

${ }^{17}$ Boxall et al (1996) apply non-parametric test methods to 'the traditional travel cost model' using a data set in which 'out of pocket' unit travel costs are researcher assessed using a, single, figure which 'represents the estimated costs of purchasing fuel and vehicle maintenance', and travel time cost is derived from hours spent travelling and on site (it is not clear whether the former are derived from distance or respondent assessed) and an estimate of the respondent's hourly wage rate (derived from reported income). They find that: there is no well-behaved utility function that an individual could be maximising, subject to a budget constraint. They reject the explanation that the individuals in their sample are irrational on the grounds that it 'seems contrary to the spirit of economic analysis'. The two explanations that they do investigate are: 'an incorrect specification of the price of a trip'; and differing preferences across individuals. In both cases they find that altering the model specification improves its consistency with revealed preference theory, though violations of the axioms are still found.

${ }^{18}$ It is interesting to note that in their meta analysis of TCM applications, Smith and Kaoru (1990) did not include an explanatory variable reflecting the conventions used to measure, non-time, travel costs.

${ }^{19}$ For these more complex specifications of the context for Randall's Difficulty, it could be that Monte Carlo simulations are the only way to investigate the magnitude of the problem. 